\title{
Community-based childhood obesity prevention intervention for parents improves health behaviors and food parenting practices among Hispanic, low- income parents
}

Laura Otterbach¹, Noereem Z. Mena', Geoffrey Greene', Colleen A. Redding ${ }^{2}$, Annie De Groot ${ }^{3}$ and Alison Tovar ${ }^{1 *}$

\begin{abstract}
Background: Given the current prevalence of childhood obesity among Hispanic populations, and the importance of parental feeding behaviors, we aimed to assess the impact of the evidence-based Healthy Children, Healthy Families (HCHF) intervention on responsive food parenting practices (FPPs) in a low-income Hispanic population.

Methods: This community-based pilot study used a non-experimental pre/post within-subjects design. Parents $(n=$ 94) of children aged 3-11 years old were recruited to participate in an 8-week, weekly group-based intervention. The intervention was delivered to nine groups of parents by trained paraprofessional educators over a two-year period. Children participated in a separate curriculum that covered topics similar to those covered in the parent intervention. Parents completed self-administered pre/post surveys, which included demographic questions, seven subscales from the Comprehensive Feeding Practices Questionnaire, and the 16-item HCHF Behavior Checklist. Descriptive statistics and paired samples t-tests were used to analyze data from parents that completed the intervention.

Results: Fifty-two, primarily Hispanic (93\%) parents completed the intervention (39\% attrition rate). For parents who completed the intervention, there was a significant increase in one of the feeding practice subscales: encouragement of balance and variety $(p=0.01)$. There were significant improvements in several parent and child diet and activity outcomes $(p \leq 0.01)$.

Conclusions: Although attrition rates were high, parents completing the study reported enjoying and being satisfied with the intervention. For parents who completed the intervention, reported 'encouragement of balance and variety', in addition to several health behaviors significantly improved. Larger studies utilizing an experimental design, should further explore the impact of the HCHF curriculum on improving certain FPPs and health behaviors that contribute to obesity.
\end{abstract}

\footnotetext{
* Correspondence: alison_tovar@uri.edu

${ }^{1}$ Department of Nutrition and Food Sciences, University of Rhode Island,

Fogarty Hall, 41 Lower College Rd, Kingston, RI 02881, USA

Full list of author information is available at the end of the article
} 


\section{Background}

Prevention of childhood obesity is an ongoing public health priority. From 2011 to 2014, 17\% of children and adolescents in the United States (U.S.) were obese [1], with Hispanic children experiencing a greater prevalence of obesity compared to non-Hispanic White children (22\% vs. $14 \%$, respectively) [1]. To reduce these racial/ ethnic disparities, obesity prevention programs and interventions for Hispanic parents are urgently needed [14]. In addition, more research is needed on communitybased interventions that actively engage parents around their child's healthy eating, physical activity and the home environment $[4,5]$. Given that parents influence their children's health behaviors and environment early in life, involving them in childhood obesity prevention is critical $[4,6-11]$.

Parents influence their child's health behaviors through the home environment and their parenting practices [4, 6-18]. Food parenting practices (FPPs) are strategies used by parents to influence both the amount and types of food a child eats $[11,13,18,19]$. It is important to teach parents about responsive feeding practices, such as role modeling healthy eating behaviors for their child; involving their child in food decisions such as grocery shopping and meal preparation; and encouraging a balanced and varied diet with their child [11-13, 15, 17-24]. These responsive FPPs have been associated with healthier diets and body mass index (BMI), while non-responsive feeding practices such as restriction and pressure have been associated with lower quality diets and higher BMIs [11-13, 15, 17-24].

Although multiple interventions aim to prevent childhood obesity [14-16, 25], few have specifically targeted the use of responsive FPPs among high-risk populations $[9,10,14,16]$, such as low-income Hispanics. Healthy Children, Healthy Families: Parents making a difference! (HCHF) is an evidence-based curriculum designed to be delivered to parents of children 3-11 years of age that focuses on developing healthy lifestyle behaviors [26-28]. Goals of the HCHF curriculum include increasing parent knowledge and skills surrounding implementation of healthy family habits, which ultimately impact child health behaviors [26-29]. Previous studies utilizing the HCHF curriculum reported significant improvements in several parent and child health behaviors using the 16-item HCHF Behavior Checklist (HCHF-BC) [26, 28-30]. While the checklist was developed specifically for the $\mathrm{HCHF}$ intervention, it does not comprehensively measure changes in FPPs using validated tools [28, 30]. Therefore, the goal of this pilot study was to assess if parents from a primarily Hispanic and low-income community, who participated in a childhood obesity intervention (HCHF) improved their responsive FPPs, specifically, 1) modeling healthy eating behaviors to their child, 2) encouraging a balanced and varied diet to their child, 3) involving children in food decisions, and 4) teaching their children about nutrition. In addition, the study aimed to assess changes in parent and child behaviors related to dietary intake and activity, using the 16-item HCHF-BC.

\section{Methods \\ Study design}

The pilot study utilized a non-experimental, pre/post within-subjects design in a community-based setting. The study involved a community partnership with Clinica Esperanza/Hope Clinic (CEHC), a clinic providing free healthcare services and programs to uninsured adults. The intervention was delivered by formally trained community paraprofessionals called Navegantes. A total of five Navegantes delivered the HCHF intervention to participants over the 2-year study period, with 23 navegantes teaching or facilitating each lesson at a time. All Navagantes were women from the surrounding community that were employed at CEHC. Over the course of 2 years (2014-2016), parents of 3-11-year-old children were recruited to participate in the study, which was framed as a community program entitled 'Niños Activos y Sanos: Healthy \& Active Children'. All of the protocols in the study were approved by the University of Rhode Island Institutional Review Board.

\section{Participants and recruitment}

Both parents and primary caregivers, such as grandparents, (all referred to as 'parents' throughout this manuscript) with a child between the ages of 3-11 years were recruited. The target population were parents living in Olneyville and South Providence, Rhode Island where the median household income is $\$ 17,538$, and $61 \%$ of the population is Hispanic [31].

Both in-person recruitment at different community settings (i.e. local parks, churches, community centers, events, etc.) and recruitment fliers were distributed throughout the community to recruit participants on a rolling basis from 2014 to 2016. In addition, researchers and Navegantes collaborated with community partners including other healthcare clinics and health-related programs to recruit parents for the study. Parents and/or primary caregivers were screened in-person or via telephone to determine eligibility. Participants were eligible to participate if they were a parent or primary caregiver of a child between 3 and 11 years of age at the beginning of enrollment and spoke English or Spanish. During the first year, 44 parents enrolled, 50 in year two $(N=94)$, with a total of nine groups of parents completing the intervention over the 2 year period. Groups occurred sequentially over the two-year study period. During the second year, the intervention was reduced by 1 week in effort to improve study retention. 


\section{Intervention}

Navegantes participated in a formal 2-day training prior to delivering the $\mathrm{HCHF}$ curriculum, which was delivered primarily in Spanish. Based on previous evidence, the HCHF curriculum was designed to provide parents with strategies to help children adopt behaviors that promote a healthy weight [26, 27]. Through problem-solving strategies and role-playing, the HCHF intervention highlights 'paths to success' (nutrition and physical behaviors) and 'keys to success' (parental strategies to facilitate progress on the path to healthy behaviors in families, which highlight several responsive FPPs, and encourage parents to use these practices at home) $[26,27]$.

For example, paths to success include 'eating more fruits and vegetables', 'eating fewer high-fat and highsugar foods,' 'playing actively', and 'limiting television and computer time' $[26,27]$. Examples of keys to success include setting a good example for their child (modeling), and offering healthy choices within limits (guiding, or encouraging a balanced and varied diet) [26, 27].

Parents attended 90-min, weekly sessions of $\mathrm{HCHF}$, which were conducted on Wednesday evenings, usually beginning at 5:30 pm. Written informed consent was obtained from all participants. Parents completed written informed consent forms to participate in the study and informed assent/written permission forms for their child if they were under the age of 7 years. Modified forms were used to allow children over the age of seven to better understand the study and provide written informed assent to participate. After consent was obtained from all participants, parents and children completed anthropometric measurements and parents then completed a written survey. Researchers were present during completion of consent forms and surveys to answer questions, assist parents who could not read or write, and provide clarification as needed. All study materials were available in both English and Spanish. The intervention was designed for the parents, given their role in shaping their child's environment and behaviors. During the sessions however, childcare and nutrition lessons were provided to children if parents chose to bring them. Parents then returned to CEHC weekly, for a total of eight sessions to complete the intervention. At the last session, the same procedures were repeated to collect post-intervention data (with the exception of consent forms). Parents were compensated with a $\$ 10$ gift card after the first session, and a $\$ 40$ gift card following the last session. Each session also included a weekly prize (such as pedometers, mixing bowls, and spatulas) for parents and their children in addition to raffle prizes (such as food prep equipment, small kitchen tools).

\section{Measures}

\section{Anthropometrics}

Standing height and weight measurements of each parent-child dyad were taken using standardized procedures [32], taken in duplicate. Parent's BMI was calculated based on their height and weight. Pre and post-intervention BMI percentiles were calculated for children using age- and sex-specific references [32, 33].

\section{Survey}

The self-administered survey consisted of 84 questions and parents answered questions as it pertained to their child that was consented to participate in the study. Parents with more than one child between ages 3-11 were instructed to base their responses on their youngest child within that age range. The decision to do this was driven by the literature on the importance of shaping health behaviors early in life given that these track into later childhood $[4,6,7,9,10,16,21]$.

Parents were asked to report on the following sociodemographic characteristics: age, sex, ethnicity, race, education level, number/ages of children, marital status, if they were born in the U.S., number of years in the U.S., employment status, health insurance status, annual household income, child date of birth, and child gender.

Reported food parenting practices were assessed using seven subscales from the previously validated CFPQ [34], including modeling ( 4 items; $\alpha=0.79$ ), involvement (3 items; $\alpha=0.89$ ), encouraging balance and variety ( 4 items; $\alpha=0.72$ ), and teaching about nutrition (3 items; $\alpha=0.42$ ). Response options, ranged on a scale from disagree (1), disagree slightly (2), neutral (3), slightly agree (4), to agree (5) [34]. Subscale means were calculated for the seven subscales, with a higher score on each subscale indicating greater agreement with the corresponding practice.

To assess frequency of parent and child health behaviors, including dietary and physical activity/screen time behaviors (11 items), and home environment/parenting behaviors (5 items), parents completed the self-reported 16-item HCHF$\mathrm{BC}$ [30]. Each item was assessed using a 5-point response scale from least to most frequent options in a range of frequencies appropriate to each reported behavior [30]. For example, for some of the questions response options ranged from (1) once in a while, (2) 1-2 days each week, (3) 3-4 days each week, (4) 5-6 days each week, to (5) every day or from (1) almost never, (2) 1-3 days each week, (3) 4-6 days each week, (4) once each day, to (5) 2 or more times each day. Mean scores for each item were calculated for analysis.

In addition to study objectives focused on parental feeding and diet and activity measures, a brief evaluation survey (14 questions) was provided to parents at the end of the final HCHF session, in effort to obtain their opinions and feedback on the program. Twenty participants that completed the study filled out an evaluation survey (surveys were provided in both English and Spanish).

\section{Statistical analysis}

Post-hoc analysis was completed to assess if there were significant changes between demographic variables for 
study completers vs. non-completers. Chi-square tests for categorical variables and an ANOVA for continuous variables were completed to compare demographics between completers and non-completers. Paired samples t-tests were performed to assess for statistically significant changes pre/post intervention for seven CFPQ subscales and the 16-item HCHF-BC. Given that this was a pilot study to assess the preliminary efficacy of the intervention, it was not adequately powered for multivariate analyses. To account for multiple comparisons, a conservative significance level was set post hoc for the $\mathrm{t}$-tests at $p \leq 0.01$. The datasets used and/or analyzed during the current study are available from the corresponding author on reasonable request.

To assess parent participation, attendance was recorded at each session. Parents were considered study completers and were included in data analyses if they attended four or more of the eight sessions in year one, or three or more of the seven sessions in year two. To assess intervention fidelity (described as the extent to which the intervention is delivered as it was intended) [35], 59\% of the HCHF sessions were observed by a trained research assistant using a previously-developed observation checklist. All statistical analysis was performed using SPSS version 23.

\section{Results}

Of the 94 parents who consented to participate over the 2 year study, nine did not complete baseline measurements, and were therefore excluded from analysis, leaving a total of 85 participants. Throughout the 2-year period, 33 parents dropped out of the intervention (i.e. did not return to the program sessions and/or did not complete post-intervention measures) and were therefore considered non-completers, leaving $n=52$ participants with both baseline and post-intervention data (attrition rate of 39\%). Figure 1 depicts a flow diagram showing the recruitment/ consent process. Study completers were significantly older as compared to non-completers (39.9 vs. 34.4 mean years of age, respectively), $(p=0.031)$ (see Table 1 ).

Of the 85 parents at baseline, $94 \%$ were female and Hispanic with a mean age of 37.6 years. Less than a third
(30\%) of parents had less than a high school degree, over half (64\%) reported an annual household income of $\$ 15,000$ or less and the majority $(79 \%)$ were not born in the U.S. (Table 1). At baseline, over $75 \%$ of the parents were either overweight or obese. Of the participating children, mean age was $5.9 \pm 2.8$ years, $56 \%$ were female, and almost half (49\%) were either overweight or obese. Intervention fidelity was high (97\%), indicating that the Navegantes delivered the intervention as it was intended based on the HCHF curriculum protocol.

For responsive FPPs, there was a significant increase in the frequency of reported use of encouraging balance and variety ( 4.5 pre, 4.63 post, $p=0.01$; Effect size (Cohens d $=0.263$ ). There were increases in the frequency of other responsive FPPs including modeling, involvement, and teaching about nutrition, however these changes were not statistically significant. For outcomes related to nonresponsive FPPs, changes were not significant (Table 2).

For changes in parent and child behaviors related to dietary intake and physical activity, there were significant increases in frequency reported intake of fruit (2.9 pre, 3.7 post; $p<0.001)$, vegetable ( 2.9 pre, 3.6 post; $p<$ 0.001 ) and low-fat dairy products for parents, (3.1 pre, 3.7 post; $p=0.003$ ). Parents significantly increased the frequency of their own reported physical activity ( 2.5 pre, 2.9 post; $p=0.006$ ) (Table 3 ).

There were also changes in measures related to the home food environment. Reported fruit availability significantly increased (4.3 pre, 4.6 post; $p=0.009$ ), while energy dense snack availability (2.4 pre, 1.8 post; $p=$ 0.001 ) and fast food intake (1.7 pre, 1.3 post; $p=0.003$ ) significantly decreased. The changes in reported parental use of food autonomy (parent letting their child decide how much to eat), and the frequency of family meals were not significant (Table 4).

Parents who completed the evaluation survey $(n=20)$ were very satisfied with the intervention. For example, they all selected 'agree' to the following statements; 'I enjoyed coming to HCHF sessions', 'I would recommend HCHF to my friends and family', 'What I learned in

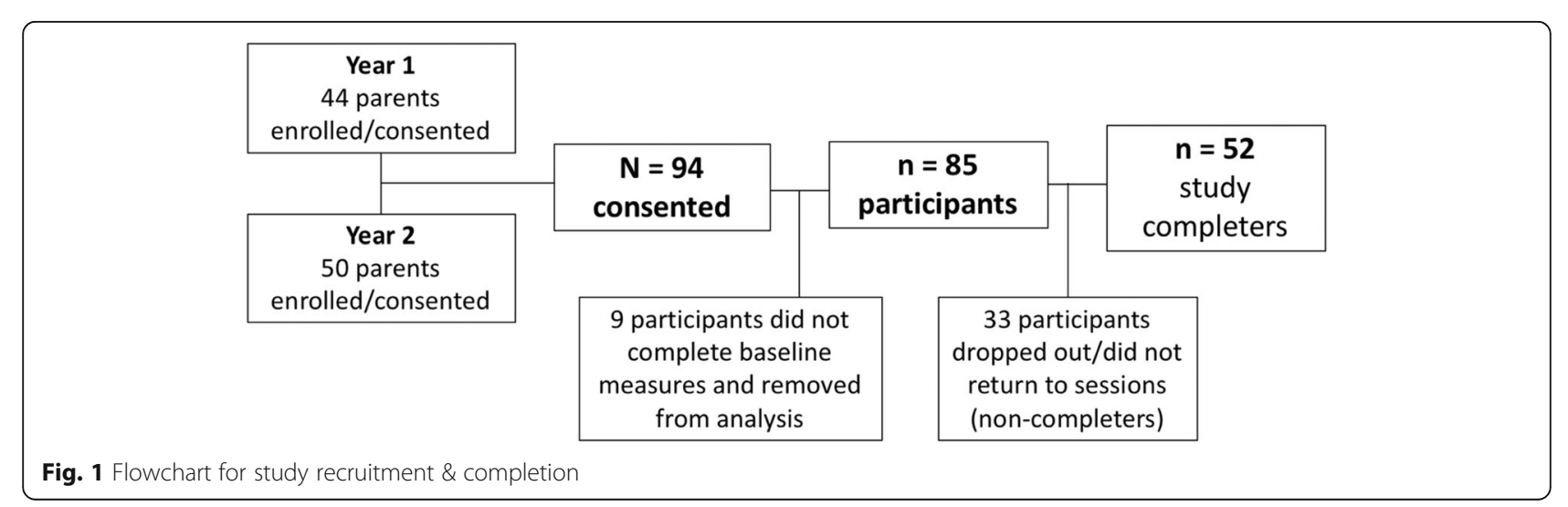


Table 1 Baseline characteristics of NASA participants $(n=85)$

\begin{tabular}{|c|c|c|c|}
\hline \multirow[t]{2}{*}{ Participant characteristics } & $\begin{array}{l}\text { All parents } \\
(n=85)\end{array}$ & \multirow{2}{*}{$\begin{array}{l}\text { Study completers } \\
(n=52) \\
n(\%)\end{array}$} & \multirow{2}{*}{$\begin{array}{l}\text { Non-completers } \\
(n=33) \\
n(\%)\end{array}$} \\
\hline & $n(\%)$ & & \\
\hline \multicolumn{4}{|l|}{ Sex } \\
\hline Female & $81(95.3)$ & $50(96.2)$ & $30(90.9)$ \\
\hline Age (mean $\pm S D)$ & $37.6 \pm 11.3$ & $39.9 \pm 10.9^{\mathrm{a}}$ & $34.4 \pm 11.1^{\mathrm{a}}$ \\
\hline \multicolumn{4}{|l|}{ Hispanic/Latino } \\
\hline Yes & $78(91.8)$ & $49(94.2)$ & $29(87.9)$ \\
\hline \multicolumn{4}{|l|}{ Race (check all that apply) } \\
\hline White & $36(42.4)$ & $23(44.2)$ & $13(39.4)$ \\
\hline African-American & $10(11.8)$ & $7(13.5)$ & $3(9.1)$ \\
\hline American Indian/Alaskan Native & $1(1.2)$ & $0(0.0)$ & $1(3.0)$ \\
\hline More than once race & $9(10.6)$ & $5(9.6)$ & $4(12.1)$ \\
\hline Wish not to answer/don't know & $10(11.8)$ & $4(7.7)$ & $6(18.2)$ \\
\hline Did not answer/Missing & $19(22.4)$ & $13(25)$ & $6(18.2)$ \\
\hline \multicolumn{4}{|l|}{ Education } \\
\hline Less than high school & $25(29.4)$ & $13(24.9)$ & $12(36.4)$ \\
\hline High school graduate/GED & $24(28.2)$ & $17(32.7)$ & $7(21.2)$ \\
\hline Post High School Trade/Technical school & $9(10.6)$ & $7(13.5)$ & $2(6.1)$ \\
\hline Some college or higher & $27(31.7)$ & $15(28.9)$ & $12(36.4)$ \\
\hline \multicolumn{4}{|l|}{ Living with Spouse } \\
\hline No & $45(52.9)$ & $26(50.0)$ & $19(57.6)$ \\
\hline \multicolumn{4}{|l|}{ Marital Status } \\
\hline Never Married & $26(30.6)$ & $12(23.5)$ & $14(42.4)$ \\
\hline Married & $32(37.6)$ & $21(41.2)$ & $11(33.3)$ \\
\hline Divorced/Separated or Widowed & $26(30.6)$ & $18(35.3)$ & $8(24.3)$ \\
\hline \multicolumn{4}{|l|}{ Born in the U.S. } \\
\hline No & $67(78.8)$ & $43(82.7)$ & $24(72.7)$ \\
\hline Years in the U.S. (mean \pm SD) & $13.0 \pm 10.3$ & $12.4 \pm 9.7$ & $14.1 \pm 11.4$ \\
\hline \multicolumn{4}{|l|}{ Employment Status } \\
\hline Employed Full time (> 35 hrs/wk) & $24(28.2)$ & $11(21.2)$ & $13(39.4)$ \\
\hline Employed Part time (<35 hrs/wk)/Seasonally & $21(24.7)$ & $14(26.9)$ & $7(21.2)$ \\
\hline Unemployed/Looking for work & $25(29.4)$ & $17(32.7)$ & $8(24.2)$ \\
\hline Homemaker & $13(15.3)$ & $10(19.2)$ & $3(9.1)$ \\
\hline Student & $1(1.2)$ & $0(0.0)$ & $1(3.0)$ \\
\hline \multicolumn{4}{|l|}{ Health Insurance } \\
\hline Yes & $53(62.4)$ & $32(69.6)$ & $21(63.6)$ \\
\hline \multicolumn{4}{|l|}{ Annual Household Income } \\
\hline$\$ 15,000$ or less & $43(50.6)$ & $29(55.8)$ & $14(42.4)$ \\
\hline$\$ 15,000-\$ 30,000$ & $15(17.6)$ & $9(17.3)$ & $6(24)$ \\
\hline$\$ 30,000-\$ 45,000$ & $8(9.4)$ & $3(5.8)$ & $5(15.2)$ \\
\hline More than $\$ 45,000$ & $2(2.4)$ & $2(3.8)$ & $0(0.0)$ \\
\hline \multicolumn{4}{|l|}{ Parent Baseline BMI score $\left(\mathrm{kg} / \mathrm{m}^{2}\right)$} \\
\hline Underweight (< 18.5) & $0(0.0)$ & $0(0.0)$ & $0(0.0)$ \\
\hline Normal Weight (18.5 - 24.9) & $16(19.2)$ & $12(22.8)$ & $4(12.0)$ \\
\hline
\end{tabular}


Table 1 Baseline characteristics of NASA participants $(n=85)$ (Continued)

\begin{tabular}{|c|c|c|c|}
\hline \multirow[t]{2}{*}{ Participant characteristics } & $\begin{array}{l}\text { All parents } \\
(n=85)\end{array}$ & $\begin{array}{l}\text { Study completers } \\
(n=52)\end{array}$ & $\begin{array}{l}\text { Non-completers } \\
(n=33)\end{array}$ \\
\hline & $n(\%)$ & $n(\%)$ & $n(\%)$ \\
\hline Overweight (25.0 - 29.9) & $25(30)$ & $16(30.4)$ & $9(27.0)$ \\
\hline Obese (30.0 or higher) & $38(49.4)$ & $23(43.7)$ & $17(51.0)$ \\
\hline \multicolumn{4}{|l|}{ Child Baseline BMI Percentile } \\
\hline Underweight (<5th) & $1(1.2)$ & $1(2.3)$ & $1(3.8)$ \\
\hline Normal Weight (5th $-<85$ th) & $32(37.7)$ & $20(46.5)$ & $12(46.2)$ \\
\hline Overweight (85th - <95th) & $12(14.1)$ & $9(20.9)$ & $4(15.4)$ \\
\hline Obese ( $\geq 95$ th) & $40(47.0)$ & $13(30.2)$ & $9(34.6)$ \\
\hline Child Age (mean \pm SD) & $5.9 \pm 2.8$ & $5.8 \pm 2.5$ & $5.9 \pm 3.3$ \\
\hline \multicolumn{4}{|l|}{ Child Gender } \\
\hline Female & $46(54.1)$ & $28(53.8)$ & $18(54.5)$ \\
\hline
\end{tabular}

Values above that do not add to $100 \%$ reflect missing data

Abbreviations: NASA Ninos Activos y Sanos/Healthy \& Active Children (Name of the program), SD Standard deviation, GED General Education Diploma, U.S. United States, Hrs Hours, Wk Week, BMI Body Mass Index

${ }^{a}$ Differences between variables for completers and non-completers were significant $(p<0.05), p=0.031$

HCHF is useful for me and my family', and 'I learned new parenting skills that help me get along better with my children.' For questions pertaining to time and location, $95 \%$ of participants agreed that the time that the sessions were held was convenient for them, while $85 \%$ agreed that the location was convenient for them. Through open-ended questions, participants shared what they liked the most of the intervention which included being able to make changes in their homes, learning about the importance of eating healthy meals and how to share them with their children, in addition to their shared experiences with other parents.

\section{Discussion}

This pilot study assessed preliminary changes in parents' use of parent-reported FPPs and diet and activity behaviors of parents and children pre/post participation in the evidenced-based HCHF intervention. Recruitment and retention of this population was a challenge. For parents that did complete the intervention, the frequency of parent-reported encouragement of balance and variety increased. Although changes in other FPPs (both responsive and non-responsive) were not significant, trends toward improvement in most FPPs were observed. There were also improvements in reported dietary intake and physical activity measures (fruit, vegetable, and soda intake for parents, and parent-reported low-fat dairy intake and physical activity for their children). Parents also reported changes in measures related to the home food environment, including a significant increase in fruit availability and a significant decrease in energy dense snack availability and fast food availability for their children. Given the pilot nature of this work and the high rate of attrition, results should be interpreted with caution. Future studies should consider testing the effectiveness of the HCHF intervention using an experimental design and exploring FPPs as possible mediators of healthy eating and obesity.

The HCHF curriculum highlights healthy eating patterns and teaches parents ways to encourage healthy eating habits with their children. The HCHF curriculum may have had the greatest impact on encouragement of

Table 2 Parent pre/post intervention FPPs using Subscales from the CFPQ $(n=52)$

\begin{tabular}{|c|c|c|c|c|c|c|c|c|}
\hline \multirow[t]{2}{*}{ CFPQ subscale } & \multicolumn{2}{|l|}{ Pre } & \multicolumn{2}{|l|}{ Post } & \multicolumn{2}{|c|}{ 95\% Confidence Interval of the Difference } & \multirow{2}{*}{$\begin{array}{l}\text { Effect size } \\
\text { (Cohens d) }\end{array}$} & \multirow[t]{2}{*}{$p$-value } \\
\hline & $\overline{\text { Mean }}$ & SD & $\overline{\text { Mean }}$ & SD & Lower & Upper & & \\
\hline Modeling & 4.47 & 0.75 & 4.62 & 0.65 & -3.59 & 0.07 & 0.20 & 0.17 \\
\hline Encouragement of Balance and Variety & 4.50 & 0.52 & 4.63 & 0.56 & -0.29 & 0.04 & 0.26 & $0.01^{*}$ \\
\hline Involvement & 3.90 & 0.97 & 4.03 & 0.99 & -0.49 & 0.24 & 0.12 & 0.48 \\
\hline Teaching About Nutrition & 3.73 & 0.72 & 3.87 & 0.58 & -0.34 & 0.06 & 0.21 & 0.17 \\
\hline Restriction for Health & 3.80 & 0.88 & 3.86 & 1.04 & -0.35 & 0.23 & 0.07 & 0.66 \\
\hline Restriction for Weight Control & 3.04 & 1.05 & 3.17 & 1.07 & -0.42 & 0.14 & 0.16 & 0.33 \\
\hline Food as Reward & 3.09 & 0.96 & 2.93 & 0.95 & -0.19 & 0.50 & 0.14 & 0.38 \\
\hline
\end{tabular}

* $p \leq 0.01$ denoted statistically significant difference between pre/post measures from the CFPQ subscale 
Table 3 Parent-reported pre/post intervention diet and physical activity outcomes from the HCHF-BC $(n=52)$

\begin{tabular}{|c|c|c|c|c|c|c|c|}
\hline \multirow[t]{2}{*}{ Item on HCHF-BC } & \multicolumn{2}{|l|}{ Pre } & \multicolumn{2}{|l|}{ Post } & \multicolumn{2}{|c|}{ 95\% Confidence Interval of the Difference } & \multirow[t]{2}{*}{$p$-value } \\
\hline & Mean & SD & Mean & SD & Lower & Upper & \\
\hline Parent Fruit Intake & 2.98 & 1.48 & 3.74 & 1.17 & -1.14 & -0.38 & $0.000^{* *}$ \\
\hline Parent Vegetable Intake & 2.92 & 1.34 & 3.58 & 1.05 & -0.97 & -0.35 & $0.000^{* *}$ \\
\hline Parent Soda Intake & 1.72 & 1.17 & 1.45 & 0.90 & -0.03 & 0.59 & 0.079 \\
\hline Parent Low-Fat Dairy Intake & 3.12 & 1.36 & 3.66 & 1.36 & -0.88 & -0.20 & $0.003^{*}$ \\
\hline Parent Physical Activity & 2.45 & 1.51 & 2.92 & 1.46 & -0.80 & -0.14 & $0.006^{*}$ \\
\hline Child Fruit Intake & 4.04 & 1.03 & 4.10 & 1.13 & -0.39 & 0.27 & 0.714 \\
\hline Child Vegetable Intake & 2.88 & 1.38 & 3.18 & 1.20 & -0.66 & 0.05 & 0.087 \\
\hline Child Low-Fat Dairy Intake & 3.28 & 1.34 & 3.72 & 1.20 & -0.84 & -0.04 & 0.033 \\
\hline Child Soda Intake & 1.55 & 0.89 & 1.55 & 1.10 & -0.27 & 0.27 & 1.00 \\
\hline Child Physical Activity & 2.90 & 1.49 & 3.53 & 1.30 & -1.04 & -0.22 & $0.003^{*}$ \\
\hline Child Screen Time & 2.20 & 0.78 & 2.02 & 0.71 & -0.05 & 0.41 & 0.118 \\
\hline
\end{tabular}

${ }^{*} p \leq 0.01,{ }^{* *} p \leq 0.001$ denoted statistically significant difference between pre/post measures from the HCHF Behavior Checklist

balance and variety due to the intervention content and the parent's ability to implement this practice in the home. Previous studies focusing on FPPs have targeted mostly non-responsive practices; for example, one longitudinal study found that non-responsive FPPs at 6,12 , and 24 months post participation in a parent-centered childhood obesity treatment program decreased significantly at each time point [36]. The longitudinal study had a longer treatment intervention compared to the present study and also focused on non-responsive FPPs; it is possible that it is easier for parents to extinguish non-responsive FPPs versus learning about new and responsive practices [20]. Using more responsive practices however supports the development of healthy eating, favorable diet quality and weight outcomes over time [13, 18, 19, 21-24, 36, 37]. It is possible that there was not as much change as expected for several of the responsive FPPs given that they may be harder practices to operationalize in the home setting such as role modeling or involving children. The mean baseline scores for these other practices were also relatively high to begin with (mean $=3.7-4.5$ ), creating ceiling effects for these measures. In addition, although the CFPQ is a validated tool, it has not been validated in this specific population (i.e. Hispanic, low-income), and future validation with these populations is needed [34].
The improvements seen in reported parent and child diet and activity behaviors are similar to previous studies utilizing the HCHF intervention, where significant improvements in parent-reported parent and child diet behaviors, including significant increases for fruit, vegetable, and low-fat dairy intake, and significant reductions in parent soda intake were found [28, 29]. These findings are not surprising in light of the topics thoroughly covered during the curriculum, including the importance of fruit and vegetable intake and drinking water or milk instead of sugar-sweetened beverages [2629]. Although the targeted population was different from previously published studies, the results from this pilot study are consistent and support the possible efficacy of this intervention in improving health behavior outcomes for parents and children, particularly in low-income, Spanish-speaking populations.

Certain aspects of this study require additional comment. It is well known that participant recruitment and retention can be challenging in health-related studies and programs that aim to reach both parents and children [38-42]. In the present study, the attrition rate of parents was $40 \%$. Furthermore, parents that completed the study were older than non-completers. Our experience is similar to that of other researchers where

Table 4 Parent-reported pre/post intervention parenting and home food environment outcomes from the HCHF-BC $(n=52)$

\begin{tabular}{|c|c|c|c|c|c|c|c|}
\hline \multirow[t]{2}{*}{ Item on HCHF-BC } & \multicolumn{2}{|l|}{ Pre } & \multicolumn{2}{|l|}{ Post } & \multicolumn{2}{|c|}{ 95\% Confidence Interval of the Difference } & \multirow[t]{2}{*}{$p$-value } \\
\hline & Mean & SD & $\overline{\text { Mean }}$ & SD & Lower & Upper & \\
\hline Autonomy & 3.25 & 1.55 & 3.71 & 1.35 & -1.03 & 0.09 & 0.096 \\
\hline Family Meals & 4.08 & 1.28 & 3.78 & 1.40 & -0.05 & 0.64 & 0.096 \\
\hline Fruit Availability & 4.30 & 0.91 & 4.58 & 0.70 & -0.49 & -0.07 & $0.009^{*}$ \\
\hline Energy Dense Snack Availability & 2.39 & 1.27 & 1.80 & 0.87 & 0.27 & 0.92 & $0.001^{*}$ \\
\hline Fast Food Availability & 1.65 & 0.77 & 1.33 & 0.55 & 0.12 & 0.51 & $0.003^{*}$ \\
\hline
\end{tabular}

${ }^{*} p \leq 0.01$ denoted statistically significant difference between pre/post measures from the HCHF Behavior Checklist 
recruiting and retaining low-income populations in health-related studies remains difficult, especially those "hardest to reach" [41, 43]. Evidence suggests that the most common barriers to recruitment and retention include socioeconomic status, education level, study location (school vs. home vs. community) and program/ intervention targets (i.e. parents or children only vs. parent and children), all of which may have affected retention in the current study $[39,42]$. Common reported barriers of parent participation in this study, included transportation, parents' work schedules and competing demands on family time [38]. Despite these barriers, the participants that were engaged continued to return to sessions and in fact requested additional sessions and education. To try and overcome the recruitment and retention challenges, barriers to study participation were reduced by working with a local community clinic, providing child care, healthy meals, and in some cases, transportation to the intervention. In order eliminate the health disparities experienced by low-income, ethnic minorities, continued efforts to reduce participation barriers in research studies are needed. Innovative approaches, including comprehensive policies and evidence-based strategies to improve recruitment and retention is warranted [43].

Given the funding mechanism and pilot nature of the study, an experimental design was not feasible. Findings need to be interpreted with caution given the lack of a control group and high attrition rates; significant results may be attributable to other factors and not necessarily the intervention itself. For example, participants may have been subjected to the observer-expectancy effect, as the study was described to participants as a health program for parents with the aim to improve the health of their families. In addition, behaviors were selfreported by parents, and therefore actual behaviors were not observed. Despite these limitations, the study utilized an evidence-based curriculum in a communitybased setting, and was able to reach an at-risk population. By targeting a population served by a free clinic in a low-income area, the intervention was able to reach Hispanic and low-income parents of children who are disproportionately at risk for obesity [1-3, 31, 44]. Future studies should continue to explore cost-effective intervention strategies to engage low-income parents and assess long-term changes in behavior.

\section{Conclusions}

This pilot study found that participation in the HCHF intervention by a primarily low-income and Hispanic population increased the reported frequency of encouragement of balance and variety, a responsive FPP, which is associated with favorable weight status and diet habits in children $[6-8,12,13,21,24]$.
However, the study is a pilot and would benefit from further randomized studies to examine evidence of effectiveness of this intervention in similar populations. Although there are several obesity prevention studies, few have specifically targeted or measured FPPs, and few have taken a family-based approach $[4,9,10,14,16]$. Interventions to prevent childhood obesity may include some information on modifying FPPs, but few have had a comprehensive focus and/or have not measured changes in these practices pre/post intervention $[36,37,45,46]$.

Future interventions should focus on improving both responsive and non-responsive FPPs [6, 11-13, 19]. The results of the current study highlight the importance of possibly targeting those responsive FPPs and parenting behaviors surrounding the home food environment in health interventions aimed at reducing childhood obesity risk. These results add to the current literature on interventions focused on FPPs in a population at higher risk for obesity, by a targeting low-income, Hispanic population.

\section{Abbreviations}

BMl: Body mass index; CEHC: Clinica Esperanza/Hope Clinic;

CFPQ: Comprehensive feeding practices questionnaire; FPP: Food parenting practice; HCHF: Healthy children, healthy families; HCHF-BC: Healthy children, healthy Families behavior checklist; U.S.: United States

\section{Acknowledgements}

This research was funded by a Blue Cross Blue Shield of Rhode Island Blue Angel Community Health Grant, awarded to CEHC in partnership with the University of Rhode Island. The authors thank the navegantes (Damaris Rosales, Luz Betancur, Ingrid Castillo, Cindy Estrada, Brenda Veliz) and program/CEHC staff (Jacob Buckley, Erik Simpanen) and the CEHC staff/ volunteers, all of who provided their time and dedication throughout the study. We also thank Noereem Mena and Fatima Tobar for delivering the child curriculum during year 1 and year 2 of the study, respectively. We thank all research assistants from the URI Community Nutrition and Childhood Obesity Prevention research group (Megan Fallon, Margaret Garcia, Maggie Tsai) for their assistance with data collection. We thank Candace Corbeil for her assistance with data analysis. We also thank Dr. Kathleen Webster for her input regarding statistical analysis. Thank you to Dr. Katherine Dickin, of Cornell University for her support during study implementation and review of this manuscript. We thank the Cornell University/creators of HCHF for creating and sharing this intervention for use in this study. We would finally like to thank all of the parents, children, and families that participated in this study.

\section{Funding}

The current study was funded by a Blue Angel Community Health Grant received Blue Cross Blue Shield of Rhode Island. This work was also supported by the USDA National Institute of Food and Agriculture, [Hatch/Tovar/ 1001894].

\section{Availability of data and materials}

The datasets used and/or analyzed during the current study are available from the corresponding author on reasonable request.

\section{Authors' contributions}

LO used this project to complete her Master's thesis work at the University of Rhode Island and drafted the manuscript. LO's responsibilities included overseeing the intervention delivery, communicating with navegantes, organizing materials, collecting and entering data and assisting with data analysis and interpretation. AT oversaw all aspects of the study and reviewed drafts of the manuscript. AD is the Medical Director of Clinica Esperanza/ Hope Clinic which was the community setting for the current study, she was involved in writing the grant for this study and reviewing drafts of the 
manuscript. NM assisted in data collection, manuscript development, and developing and delivering the nutrition curriculum for children while their parents participated in the intervention. GG and CR contributed to the development of the overall study design (i.e. research methods and objectives/research questions), in addition manuscript development and review. All authors have given final approval of the manuscript for submission for publication.

\section{Ethics approval and consent to participate}

The research protocol for the current study was reviewed and approved by the University of Rhode Island Institutional Review Board (IRB). Written informed consent was obtained from all participants. Parents completed written informed consent forms to participate in the study and provide data measures for both themselves and their child. Parents also completed informed assent/written permission forms (if their child was under 7 years of age) to participate in the study. Modified forms were used to allow children over the age of seven to better understand the study and provide written informed assent to participate.

\section{Consent for publication}

Not applicable.

\section{Competing interests}

The authors declare that they have no competing interests.

\section{Publisher's Note}

Springer Nature remains neutral with regard to jurisdictional claims in published maps and institutional affiliations.

\section{Author details}

${ }^{1}$ Department of Nutrition and Food Sciences, University of Rhode Island, Fogarty Hall, 41 Lower College Rd, Kingston, RI 02881, USA. ${ }^{2}$ Cancer Prevention Research Center and Department of Psychology, University of Rhode Island, Chafee Hall, 142 Flagg Road, Kingston, RI 02881, USA. ${ }^{3}$ Institute for Immunology and Informatics, University of Rhode Island, Shepard Building, 80 Washington Street, Providence, RI 02903, USA.

Received: 24 October 2017 Accepted: 15 March 2018 Published online: 27 March 2018

\section{References}

1. Ogden CL, Carroll MD, Lawman HG, Fryar CD, Kruszon-Moran D, Kit BK, Flegal KM. Trends in obesity prevalence among children and adolescents in the United States, 1988-1994 through 2013-2014. JAMA. 2016;315(21):2292-9.

2. The burden of overweight and obesity in Rhode Island. In: Initiative for a healthy weight program. Providence: The Rhode Island Department of Health Initiative for a Healthy Weight Program; 2011.

3. Pratt CA, Loria CM, Arteaga SS, Nicastro HL, Lopez-Class M, de Jesus JM, Srinivas P, Maric-Bilkan C, Schwartz Longacre L, Boyington JEA, et al. A systematic review of obesity disparities research. Am J Prev Med. 2017:53(1):113-22.

4. Ash T, Agaronov A, Young T, Aftosmes-Tobio A, Davison KK. Family-based childhood obesity prevention interventions: a systematic review and quantitative content analysis. Int J Behav Nutr Phys Act. 2017;14(1):113.

5. Wang Y, Cai L, Wu Y, Wilson RF, Weston C, Fawole O, Bleich SN, Cheskin LJ, Showell NN, Lau BD, et al. What childhood obesity prevention programmes work? A systematic review and meta-analysis. Obes Rev. 2015;16(7):547-65.

6. Golan M. Parents as agents of change in childhood obesity - from research to practice. Int J Pediatr Obes. 2006;1 (2):66-76.

7. Golan M, Crow S. Parents are key players in the prevention and treatment of weight-related problems. Nutr Rev. 2004;62(1):39-50.

8. Golan M, Weizman A. Familial approach to the treatment of childhood obesity: conceptual mode. J Nutr Educ. 2001;33(2):102-7.

9. Davison KK, Jurkowski JM, Lawson HA. Reframing family-centred obesity prevention using the family ecological model. Public Health Nutr. 2013; 16(10):1861-9.

10. Davison KK, Lawson HA, Coatsworth JD. The family-centered action model of intervention layout and implementation (FAMILI): the example of childhood obesity. Health Promot Pract. 2012;13(4):454-61.

11. Patrick H, Hennessy E, McSpadden $K$, Oh A. Parenting styles and practices in children's obesogenic behaviors: scientific gaps and future research directions. Child Obes. 2013;9(Suppl):S73-86
12. Rodgers RF, Paxton SJ, Massey R, Campbell KJ, Wertheim EH, Skouteris H, Gibbons K. Maternal feeding practices predict weight gain and obesogenic eating behaviors in young children: a prospective study. Int J Behav Nutr Phys Act. 2013;10:24.

13. Sleddens EF, Kremers SP, Stafleu A, Dagnelie PC, De Vries NK, Thijs C. Food parenting practices and child dietary behavior. Prospective relations and the moderating role of general parenting. Appetite. 2014;79:42-50.

14. Olson S. Obesity in the early childhood years: state of the science and implementation of promising solutions: workshop in brief. National Academies of Sciences, Engineering, and Medicine; 2016.

15. Shloim N, Edelson LR, Martin N, Hetherington MM. Parenting styles, feeding styles, feeding practices, and weight status in 4-12 year-old children: a systematic review of the literature. Front Psychol. 2015;6:1849.

16. Birch LL, Ventura AK. Preventing childhood obesity: what works? Int J Obes. 2009;33(Suppl 1):S74-81.

17. Pinard CA, Yaroch AL, Hart MH, Serrano EL, McFerren MM, Estabrooks PA. Measures of the home environment related to childhood obesity: a systematic review. Public Health Nutr. 2012;15(1):97-109.

18. Vollmer RL, Mobley AR. Parenting styles, feeding styles, and their influence on child obesogenic behaviors and body weight. A review. Appetite. 2013; 71:232-41.

19. Vaughn AE, Ward DS, Fisher JO, Faith MS, Hughes SO, Kremers SP, MusherEizenman DR, O'Connor TM, Patrick H, Power TG. Fundamental constructs in food parenting practices: a content map to guide future research. Nutr Rev. 2016;74(2):98-117.

20. Natale RA, Messiah SE, Asfour L, Uhlhorn SB, Delamater A, Arheart KL. Role modeling as an early childhood obesity prevention strategy: effect of parents and teachers on preschool children's healthy lifestyle habits. J Dev Behav Pediatr. 2014;35(6):378-87.

21. Couch SC, Glanz K, Zhou C, Sallis JF, Saelens BE. Home food environment in relation to children's diet quality and weight status. J Acad Nutr Diet. 2014; 114(10):1569-79. e1561

22. Tschann JM, Martinez SM, Penilla C, Gregorich SE, Pasch LA, de Groat CL, Flores E, Deardorff J, Greenspan LC, Butte NF. Parental feeding practices and child weight status in Mexican American families: a longitudinal analysis. Int J Behav Nutr Phys Act. 2015:12:66.

23. Farrow CV, Haycraft E, Blissett JM. Teaching our children when to eat: how parental feeding practices inform the development of emotional eating-a longitudinal experimental design. Am J Clin Nutr. 2015;101(5):908-13.

24. Spruijt-Metz D, Li C, Cohen E, Birch L, Goran M. Longitudinal influence of mother's child-feeding practices on adiposity in children. J Pediatr. 2006;148(3):314-20.

25. Dawson-McClure S, Brotman LM, Theise R, Palamar JJ, Kamboukos D, Barajas RG, Calzada EJ. Early childhood obesity prevention in low-income, urban communities. J Prev Interv Community. 2014;42(2):152-66.

26. Dickin KL, Hill TF, Dollahite JS. The collaboration for health, activity, and nutrition in Children's environments (CHANCE): a program integrating parenting and nutrition behavioral education improves food, active play, and parenting practices in low-income families. Anaheim: Experimental Biology; 2010

27. Healthy Children, Healthy Families: Parents Making a Difference! Food and Nutrition Education in Communities. http://fnec.cornell.edu/for-partners/ curricula/hchf/. Accessed 5 Jan 2015.

28. Dickin KL, Hill TF, Dollahite JS. Practice-based evidence of effectiveness in an integrated nutrition and parenting education intervention for low-income parents. J Acad Nutr Diet. 2014;114(6):945-50.

29. Lent M, Hill TF, Dollahite JS, Wolfe WS, Dickin KL. Healthy children, healthy families: parents making a difference! A curriculum integrating key nutrition, physical activity, and parenting practices to help prevent childhood obesity. Jutr Educ Behav. 2012;44(1):90-2

30. Dickin KL, Lent M, Lu AH, Sequeira J, Dollahite JS. Developing a measure of behavior change in a program to help low-income parents prevent unhealthful weight gain in children. J Nutr Educ Behav. 2012;44(1):12-21.

31. Olneyville: action for a healthier community: Rhode Island Department of Health. Providence: Olneyville Housing Corportation; 2011.

32. Lohman TG. Advances in body composition, vol. 3. Champain: Human Kinetics Publishers; 1992

33. Centers for Disease Control and Prevention. CDC Table for calculating body mass index values for selected heights and weights for ages 2 to 20. 2000. http://www cdc.gov/growthcharts/html charts/bmiagerev.htm. Accessed Apr 2017.

34. Musher-Eizenman D, Holub S. Comprehensive feeding practices questionnaire: validation of a new measure of parental feeding practices. J Pediatr Psychol. 2007;32(8):960-72. 
35. Gearing RE, El-Bassel N, Ghesquiere A, Baldwin S, Gillies J, Ngeow E. Major ingredients of fidelity: a review and scientific guide to improving quality of intervention research implementation. Clin Psychol Rev. 2011;31(1):79-88.

36. Burrows T, Warren JM, Collins CE. The impact of a child obesity treatment intervention on parent child-feeding practices. Int J Pediatr Obes. 2010;5(1):43-50.

37. Johnson SL. Developmental and environmental influences on young Children's vegetable preferences and consumption. Adv Nutr. 2016;7(1): 220S-31S.

38. Axford N, Lehtonen M, Kaoukji D, Tobin K, Berry V. Engaging parents in parenting programs: lessons from research and practice. Child Youth Serv Rev. 2012;34(10):2061-71.

39. Cui Z, Seburg EM, Sherwood NE, Faith MS, Ward DS. Recruitment and retention in obesity prevention and treatment trials targeting minority or low-income children: a review of the clinical trials registration database. Trials. 2015;16:564.

40. Lucas PJ, Curtis-Tyler K, Arai L, Stapley S, Fagg J, Roberts H. What works in practice: user and provider perspectives on the acceptability, affordability, implementation, and impact of a family-based intervention for child overweight and obesity delivered at scale. BMC Public Health. 2014;14:614.

41. Probstfield JL, Frye RL. Strategies for recruitment and retention of participants in clinical trials. JAMA. 2011;306(16):1798-9.

42. Coatsworth JD, Duncan LG, Pantin H, Szapocznik J. Patterns of retention in a preventive intervention with ethnic minority families. J Prim Prev. 2006;27(2):171-93.

43. Raphael JL, Lion KC, Bearer CF. Policy solutions to recruiting and retaining minority children in research. Pediatr Res. 2017;82(2):180-2.

44. Lovasi GS, Hutson MA, Guerra M, Neckerman KM. Built environments and obesity in disadvantaged populations. Epidemiol Rev. 2009;31:7-20.

45. Holland JC, Kolko RP, Stein RI, Welch RR, Perri MG, Schechtman KB, Saelens $\mathrm{BE}$, Epstein $\mathrm{LH}$, Wiffley DE. Modifications in parent feeding practices and child diet during family-based behavioral treatment improve child zBMI. Obesity (Silver Spring). 2014;22(5):E119-26.

46. Vaughn AE, Tabak RG, Bryant MJ, Ward DS. Measuring parent food practices: a systematic review of existing measures and examination of instruments. Int J Behav Nutr Phys Act. 2013;10:61.

\section{Submit your next manuscript to BioMed Central and we will help you at every step:}

- We accept pre-submission inquiries

- Our selector tool helps you to find the most relevant journal

- We provide round the clock customer support

- Convenient online submission

- Thorough peer review

- Inclusion in PubMed and all major indexing services

- Maximum visibility for your research

Submit your manuscript at www.biomedcentral.com/submit

) Biomed Central 